\title{
Menilik Dominasi Bahasa Mitos Dalam Sosiokultural Sasak
}

\author{
Zainul Muttaqin \& Mu'awanah \\ Universitas Hamzanwadi \\ Corresponden e-mail: kabarzainul@gmail.com
}

\begin{abstract}
:
The purpose of this study is to describe the process of hegemony in the language of Tithe Ringkok Ratu myth in North Masbagik Village. The problem formulation of this research is "how is the process of hegemony in the language of the myth of Timba Lingkok Ratu in North Masbagik Village? To answer the research question above, the researcher conducted the research with qualitative descriptive method and approach with the type of ethnographic research located in North Masbagik Village Masbagik Subdistrict. Furthermore, data collection techniques from this research are observation, interview and documentation. While data analysis is data reduction, data presentation, and withdrawal conclusion. The results of this study indicate that the process of hegemony in the language of the myth of Timba Lingkok Ratu in North Masbagik Village begin beliefs that are superstition, then this belief is spread from the mouth of tempest that is by the dominant party (people who hegemonies) to the dihegemoni. Furthermore, languages that are persuasive or affect the dominant party with a style of delivery that is so reliable and with strong evidence. Therefore, it can be concluded that the process of hegemony into the language of Titus Ringkok Ratu in North Masbagik Village is a process of convincing someone who is done by the dominant party to the community against Titus Timba Lingkok Ratu in North Masbagik Village with strong evidences.
\end{abstract}

Keywords: Hegemony Process, Language Myth of Rimb Enclosure Queen

\begin{abstract}
Abstrak:
Tujuan Penelitian ini adalah untuk menggambarkan tentangproses hegemoni dalam bahasa Mitos Timba lingkok Ratu di Desa Masbagik Utara. Adapun rumusan masalah dari penelitian ini adalah "bagaimanakah proses hegemoni dalam bahasa mitos Timba Lingkok Ratu di Desa Masbagik Utara? Untuk menjawab pertanyaan penelitian diatas maka peneliti melakukan penelitian dengan metode dan pendekatan deskriptif kualitatif dengan jenis penelitian etnografi yang berlokasi di Desa Masbagik Utara Kecamatan Masbagik. Selanjutnya, teknik pengumpulan data dari penelitian ini yaitu observasi, wawancara dan dokumentasi. Sedangkan analisis data adalah reduksi data, penyajian data, dan penarikan kesimpulan. Hasil penelitian ini menunjukkan bahwa proses hegemoni dalam bahasa mitos Timba Lingkok Ratu di Desa Masbagik Utara berawal keyakinan yang bersifat tahayyul, kemudian keyakinan ini disebar luaskan dari mulut kemulut yaitu oleh pihak dominan (orang yang menghegemoni) kepada orang yang dihegemoni. Selanjutnya, bahasa yang bersifat persuasif atau mempengaruhi pihak dominan dengan gaya penyampaian yang begitu meyakinkandisertai bukti-bukti yang kuat. Oleh karena itu dapat disimpulkan bahwa proses hegemonidalam bahasa Mitos Timba Lingkok Ratu di Desa Masbagik Utara adalah sebuah proses meyakinkan seseorang yang dilakukan oleh pihak dominan kepada masyarakat terhadap Mitos Timba Lingkok Ratudi Desa Masbagik Utara dengan pembuktian-pembuktian yang kuat.
\end{abstract}

Kata Kunci : Proses Hegemoni, Bahasa Mitos Timba Lingkok Ratu 


\section{Pendahuluan}

Mitos adalah tradisi lisan yang terbentuk di suatu masyarakat. Mitos memiliki asal kata dari bahasa Yunani yang artinya sesuatu yang diungkapkan. Secara pengertian mitos adalah cerita yang bersifat simbolik yang mengisahkan serangkaian cerita nyata atau imajiner. "Mitos merupakan suatu bentuk pesan atau tuturan yang wajib diyakinikebenarannya namun tidak dapat dibuktikan. Mitos bukanlah sebuahkonsep atau ide tetapi merupakan suatu cara pemberian arti. Secaraetimologis, mitos adalah suatu jenis tuturan dan sudah pasti bukansembarangan tuturan. Suatu hal yang menjadi konsen dan yang menjadisuatu yang harus diperhatikan, bahwa mitos adalah suatu sistimkomunikasi yakni suatu pesan (message) (Suprapto, 2015: 10)”.

Akan tetapi mitos tidak didefinisikan oleh objek pesan. Melainkan dengan cara menuturkan pesan tersebut misalnya dalam mitos, bukan hanya menjelaskan tentang objek pohon secara kasat mata tetapi yang penting adalah bagaimana cara menuturkan tentang pohon tersebut. Mitos berkembang di masyarakat dari mulut ke mulut dan umumnya bersifat lisan. Dengan demikian, mitos tersebut berkembang seperti ceritra lisan (folklor). Isi mitos menyangkut keyakinankeyakinan yang bersifat animisme dan dinamisme yaitu masyarakat pada zaman dahulu masih percaya tentang hal-hal yang bersifat gaib atau mistis sebagai contoh keberadaan Timba Lingkok Ratu yang dapat menyembuhkan berbagaimacam penyakit apabila seseorang mandi dan mengambil airnya. Contoh mitos tersebut terkait dengan sistem kepercayaan masyarakat setempat. Disini mitos ditampilkan sesuatu yang dekat dengan kepercayaan masyarakat berserta sifatnya yang tentu dan dijadikan teladan (Danadjaya, 1994).

Dari pendapat tersebut mengandung pengertian bahwa mitos merupakan cerita atau penuturan yang dapat dijadikan pedoman atau arah tertentu bagi sekelompok manusia. Cerita tersebut dapat berupa cerita naratif.

Dalam tataran kehidupan manusia, pengertian ini dapat dimaknai bahwa nilai dari kebenaran suatu mitos yang ada dalam masyarakat belum tentu terbukti kebenarannya, karena mitos hanyalah sebuah cara penuturan atau penyampaian informasi dari kejadian yang diamati oleh masyarakat. Nilai benar atau salah suatu mitos bergantung dari keyakinan dan kepercayaan para pelakunya saja.

Roland Barthes dalam Suprapto (2015: 3) menjelaskan bahwa "mitos termasuk dalam sistem komunikasi, namun lebih menekankan pada interaksi antara teks dengan pengalaman personal dan kultur penggunaannya". Dengan demikian, ia merupakan sebuah pesan tidak mungkin dapat menjadi sebuah objek atau sebuah konsep, atau sebuah ide. Mitos adalah sebuah model penandaan, yakni sebuah bentuk.

Menurut Kurnia (2016: 188) cara berfikir mitologis ditandai oleh duahal. "Pertama melarikan diri dari kenyataan dengan berlindung di baliksimbol-simbol yang membius dan menipu, kedua, menghindari sesuatu yangkonkret menuju sesuatu yang abstrak". Contohnya banyak; mulai daritakhayul-takhayul primitif warisan masa silam, kepercayaan laten tentangakan datangnya Ratu Adil, hingga mitos-mitos kontemporer seperti slogan“pembangunan di segala bidang" yang kenyataan sering kali adalahpembodohan di segala bidang.

"Istilah hegemoni sendiri sering dikacaukan dengan istilah ideologikarena terdapat unsur kepemimpinan dan persetujuan dari kelompokyang dihegemoni. Hal ini sangat berbeda, karena dalam hegemoni yangmempunyai struktur lebih kompleks dapat terkandung ideologi, namunbelum tentu sebaliknya" (Ratna dalam (Puspitarini, 2014:25).

Hegemoni juga banyak dipakai oleh para ahli sosiologi untukmenggambarkan suatu usaha mempertahankan kekuasaan. Artinya, bagaimanakelompok yang mendominasi berhasil 
mempengaruhi kelompok yangdidominasi untuk menerima nilai-nilai moral, politik, dan budaya darikelompok berkuasa.

"Hegemoni dikembangkan oleh seorang filsuf Marxis Italia AntonioGramsci yang menyatakan bahwa konsep hegemoni menurutnya tidaksebatas makna literal yang berupa "kepemimpinan", melainkanmencakup sesuatu yang lebih kompleks lagi, antara lain; bentukbentukpolitis, cultural, dan ideologis tertentu yang lewatnya pula suatumasyarakat yang ada (kelas Pundamental) dapat membangunkepemimpinannya" (Sujarwa, 2010:17).

Hegemoni Gramscian populer pada dekade 1970-an hingga 1980-andengan memberikan perhatian pada proses pemaknaan yang didominasi olehpraktik otoritatif. Dalam analisis Gramscian, ideologi dipahami sebagai ideyang mendukung kelompok sosial tertentu. Benet membandingkan konsep kebudayaan menurut Foucault dan Gramsci. Pusat perhatian Foucoult padapemerintahan birokrasi, sedangkan Gramsci pusat perhatiannya adalahideologi. Bagi Foucoult kekuasaan tidak mempunyai asal usul dan tidakbersifat tunggal, sedangkan kekuasaan (hegemoni) menurut Gramsci mengalirke bawah mengarah pada perjuangan kaum tertindas untuk menentang sumberkekuasaan tunggal (Ratna dalam Puspitarini, 2014: 26). Bagi Gramsci, sejarahadalah suatu proses konflik dan kompromi yang di dalamnya terdapat kelasfundamental yang nanti akan muncul sekaligus sebagai dominan dan direktif.

Peneliti mengambil judul ini karena merasa terinspirasi dengan fenomena yang terjadi di Desa Masbagik Utara yaitu tentang proses hegemonidalam bahasa mitos Timba Lingkok Ratu yang diyakini dapat menjadi obatsebagai penyembuh berbagai macam penyakit. Pertama-tama peneliti melihatbanyaknya masyarakat baik yang dari dalam desa maupun dari luar desa yangberdatangan setiap hari guna mengambil air sebagai syarat untukmenyembuhkan berbagai macam penyakit.

Sebelum peneliti mengetahuitentang hal tersebut, peneliti berasumsi bahwa masyarakat yang datang kesanabertujuan hanya sekedar mandi dan mengambil air, namun setelah penelitimeminta informasi dari salah satu orang yang terlibat dalam hal tersebuttertanya dibalik semua itu tersimpan mistik yang sangat penting dalamkehidupan sehari-hari. Secara logika mungkin hal tersebut sulit untukdipercaya bagi orang yang berpendidikan namun kebanyakan masyarakatmeyakini hal tersebut sehingga dari keyakinan mereka yang kuat itulah MitosTimba Lingkok Ratu dapat dijadikan sebagai syarat penyembuhan berbagaimacam penyakit. Kemudian yang kedua, hal yang menginspirasi peneliti untukmengambil judul ini adalah adanya Proses Hegemoni Dalam Bahasa MitosTimba Lingkok Ratu. Ketika peneliti menggali informasi dari orang yangberdatangan disana, peneliti melihat adanya proses hegemoni yang muncul. Hal ini diceritakan oleh salah satu orang yang berobat dengan cara mandi dan mengambil airnya (Amaq Saleh, 53 tahun dari Desa Suela), dia menyatakan bahwa ada orang Masbagik (Amaq Ridwan, 60 Tahun) menceritakannya tentang keajaiban yang terdapat dalam Timba Lingkok Ratu itu. Timba itu dikisahkan mengandung kekuatan gaib yang dapat menyembuhkan berbagai macam penyakit. Hal itu dibuktikan sendiri oleh Amaq Ridwan, awalnya beliau itu dulu mengidap penyakit yang kata dokter disebut penyakit TBC.

Namun setelah beliau berniat mandi dan mengambil airnya untuk penyembuhan, tidak lama kemudian setelah kurang lebih satu bulan beliau sembuh secara berangsur-angsur hingga sampai sekarang penyakitnya tidak kumat lagi. Tidak hanya Amaq Ridwan kata Amaq Saleh tetangganya pun banyak yang sudah sembuh sebab mengambil syarat untuk berobat disana. Oleh karena itu keberadaan Timba Lingkok Ratu di Desa Masbagik Utara menjadi sorotan masyarakat sebagai tempat pengobatan baik masyarakat dalam maupun dari luar desa. Dari fenomena diatas, peneliti berasumsi bahwa terdapat suatu proses hegemoni dari Timba Lingkok Ratu yaitu adanya suatu 
supremasi kelompok orang-orang yang mewujudkan doktrin terhadap orang lain dalam suatu masyarakat dimana kelompok yang didominasi oleh kelompok penguasa tidak merasa dibohongi atau diberatkan dan merasa itu sebagai hal yang benar-benar ada.

Selanjutnya hegemoni itu muncul ketika orang yang ingin mewujudkan suatu doktrin itu merasa kasihan dan turut bersimpati atas orang yang menjadi objeknya. Mereka berkeinginan untuk membantu orang yang menjadi objeknya tersebut agar mengalami seperti yang dialaminya dengan cara membujuk dan mempengaruhinya dengan berbagai bukti yang seolah-olah hal tersebut terbukti kebenarannya, padahal itu belum tentu terjadi secara akal. Sehingga orang yang menjadi objeknya itu meyakini dan mau melakukan apa yang diperintahkan tanpa ada rasa beban sedikitpun.

Oleh karena itu, proses hegemoni dalam bahasa mitos Lingkok Ratu itu terjadi ketika pihak yang dominan menggambarkan bahwa Lingkok Ratu dapat mengobati segala macam penyakit jika seseorang mandi dan mengambil airnya. Hal ini terjadi karena Lingkok Ratu tersebut dianggap mempunyai kekuatan gaib yang menyembuhkan orang yang sakit tanpa sadar mereka percaya tentang kekuatan-kekuatan mistis yang ada pada Lingkok Ratu tersebut. Dengan demikian orang yang sudah terhegemoni akan melakukan apa yang telah diceritakan sebagai bentuk dari penghegemonian tersebut. Komunikasi dua arah ini terjadi ketika proses penghemonian itu berlangsung, antara orang yang melakukan hegemoni terhadap objeknya sebagai contoh Amaq Ridwan dengan Amaq Saleh. Amaq Ridwan sebagai penghegemoni sedangkan Amaq Saleh sebagai objek yang terhegemoni. Adapun bentuk dari komunikasi dua arah itu yaitu Amaq Ridwan menceritakan Amaq Saleh tentang keajaiban yang terdapat dalam Timba Lingkok Ratu. Timba itu dikisahkan mengandung kekuatan gaib yang dapat menyembuhkan berbagai macam penyakit. Dengan berbagai bukti cerita yang diceritakan oleh Amaq Ridwan, Amaq Saleh akhirnya terhegemoni dan melakukan hal-hal yang disarankan yaitu mandi dan mengambil air Timba Lingkok Ratu untuk diminum dengan tujuan supaya penyakitnya sembuh.

Dari berbagai alasan dan fenomena di atas maka penelitian ini " Proses Hegemoni Dalam Bahasa Mitos (Timba Lingkok Ratu) di Desa Masbagik Utara” harus dikaji dengan mendalam.

Selanjutnya, metode yang akan digunakan dalam penelitian ini adalah metode etnografi yang mana prosedur dari penelitiannya melalui observasi yaitu peneliti melakukan observasi lokasi atau lapangan. Kemudian, dilanjutkan dengan mencari informan dan mewawancarai mereka yang berkaitan dengan fenomena Mitos Timba Lingkok Ratu di Desa Masbagik Utara. Terakhir, melakukan dokumentasi dengan tujuan untuk menghasilkan data deskriptif berupa kata-kata tertulis atau lisan dari orang-orang yang diamati untuk membangun sebuah pemahaman atas dasar dinamika secara holistik dari kehadiran manusia dan interaksinya dengan lingkungan.

bagaimanakah proses hegemoni dalam bahasa mitos Timba Lingkok Ratu di Desa Masbagik Utara?

\section{Metode}

Selanjutnya, jenis penelitian yang digunakan dalam penelitian ini adalahjenis penelitiankualitatif dengan metode etnografi yang mana prosedur daripenelitiannya melalui observasi lapangan, wawancara dan dokumentasi darifenomena sosiokultural dalam masyarakat. Menurut Emzir (2012) menyatakanbahwa, "Penelitian etnografi adalah suatu bentuk penelitian yang berfokus padamakna sosiologi melalui obsevasi lapangan tertutup dari fenomenasosiokultural.”

Berkaitan dengan penelitian ini yaitu proses hegemoni dalam bahasamitos di Desa Masbagik Utara, maka peneliti menggunakan pendekatanpenelitian deskriptif kualitatif dengan jenis penelitian etnografi. Karenavariabel penelitian ini berfokus pada fenomena sosial dalam masyarakat 
Selanjutnya, dalam melakukan penelitian, peneliti melakukan observasi lokasi,Populasi dalam penelitian ini adalah semua orang yang mempercayai mitos Timba Lingkok Ratu sebagai obat baik orang Masbagik Utara maupunorang luar yang datang berobat pada Timba tersebut. Sedangkan sampel daripenelitian ini adalah orang dapat memberikan informasi terkait dengan tujuanpenelitian yang dilakukan dan dapat mewakili ciri-ciri yang dimiliki olehpopulasi dari penelitian ini. Oleh karena itu, sampel dari penelitian ini adalahorang yang mandi dan minum air Timba Lingkok Ratu dengan tujuan untukmengobati penyakitnya.

Pengambilan sampel dilakukan dengan menggunakan tehnikpurposive sample. Menurut Arikunto (2010:183) menyatakan bahwa,"Purposive sample adalah teknik penentuan sampel dengan pertimbangantertentu."

Pemilihan sampel secara purposive pada penelitian ini akan berpedoman padasyarat-syarat yang harus dipenuhi sebagai berikut: a. Pengambilan sampel harus orang yang mempercayai mitos Timba LingkokRatu sebagai obat. b. Orang yang dijadikan sampel harus dapat memberikan informasi yangsebanyak-banyaknya mengenai Mitos Timba Lingkok Ratu sebagai obat.c. Orang yang dijadikan sampel mempunyai kesempatan dan bersediadijadikan sampel dalam penelitian ini.

1. Data Primer

Data primer yang digunakan dalam penelitian ini adalah data hasil observasi dan wawancara mendalam dengan para informan penelitiantentang proses hegemoni dalam bahasa mitos pada Timba Lingkok RatuDesa Masbagik Utara Kecamatan Masbagik.

\section{Data Sekunder}

Data sekunder yang digunakan dalam penelitian ini adalah data-data yang diperoleh dari dokumendokumen seperti foto-foto atau gambaryang diambil oleh peneliti dari orang yang sedang menghegemoni danorang yang sedang berobat pada Timba Lingkok Ratu tersebut. Sumberlainya adalah seperti hasil-hasil studi, survey, dan sebagainya. Penelitimenggunakan data ini untuk memperkuat penemuan dan melengkapiinformasi yang telah dikumpulkan melalui wawancara.

Tehnik Pengumpulan Data1. Pengamatan (Observasi) pengamatan berperan serta sebagai enelitian yang bercirikaninteraksi sosial yang memakan waktu cukup lama antara peneliti dengansubyek, dan selama itu data dalam bentuk catatan lapangan dikumpulkansecara sistematis dan berlaku tanpa gangguan.Dalam penelitian ini peneliti melakukan observasi partisipan, dimanapeneliti akan berbaur dan bergaul dengan warga setempat sehinggadiperoleh data informasi yang lebih mendalam mengenai proses hegemonidalam bahasa mitos khususnya Mitos Timba Lingkok Ratu yang berada diDesa Masbagik Utara Kecamatan Masbagik Kabupaten Lombok Timur.

2. Wawancarayaitu pihak pewawancara yang mengajukanpertanyaan dan pihak yang diwawancarai yang memberikan jawaban ataspertanyaan itu. Adapun maksud wawancara ini seperti yang ditegaskan olehMoleong (2013) menyatakan bahwa,"Maksud dari wawancara antara lain: menkonstruksikan mengenaiorang, kejadian, kegiatan, organisasi, perasaan, motivasi, tuntutan,kepedulian kebulatan dan lain-lain." Untuk mendapatkan data yang sesuai dengan proses hegemoni dalambahasa mitos pada Timba Lingkok Ratu Desa Masbagik Utara, penelitimelakuka wawancara yang mendalam dengan para informan yang sudahdipilih.

Dalam penelitian ini peneliti menggunakan dua macam wawancarayaitu wawancara terstruktur dan tidak terstruktur :a. Wawancara terstruktur adalah wawancara yang pewawancaranyamenetapkan sendiri masalah dan pertanyaan yang diajukan. Dalam halini, peneliti sebagai pewawancara akan mewawancarai para informanterkait dengan proses hegemoni dalam 
bahasa mitos pada Timba LingkokRatu Desa Masbagik Utara.b. Wawancara tidak terstruktur merupakan wawancara yang berbedadengan wawancara terstruktur dalam wawancara ini respondennya terdiridari orang-orang yang dipilih untuk memperoleh data yang dikehendaki,dalam penelitian ini peneliti mengajukan pertanyaan bebas tanpa terikatoleh susunan pertanyaan yang telah dipersiapkan pada instrumenpenelitian. Dalam hal ini, peneliti hanya melakukan wawancara denganpara informan yang sedang berobat pada Timba Lingkok Ratu yangberada di Desa Masbagik Utara Kecamatan Masbagik KabupatenLombok Timur.

3. Dokumentasiberupa gambar atau foto-foto yang telah diambil pada saat penelitian dan juga dokumen-dokumen baikdari tulisan, laporan dan lainnya, sepertinya Profil Desa, Monografi Desadan lainnya, dari sini peneliti memperoleh data jumlah peduduk, keadaansosial, agama yang terutama kaitannya dengan proses hegemoni dalambahasa mitos khususnya mitos Timba Lingkok Ratu yang berada di DesaMasbagik Utara Kecamatan Masbagik Kabupaten Lombok Timur.

Data yang digunakan dalam penelitian ini adalah data kualitatif yakni data-data yang diperoleh dari para informan baik orang yang menghegemoni oranglain sehingga orang itu meyakini mitos Timba Lingkok Ratu maupun orangyang dihegemoni dengan Timba Lingkok Ratu tersebut.

\section{Proses Hegemoni dalam Bahasa Mitos Timba Lingkok Ratu}

Sebagaimana yang kita ketahui bahwa hegemoni itu adalah proses menanamkan suatu keyakinan terhadap orang lain supaya dapat mengikuti apa yang kita yakini baik secara sadar maupun tanpa sadar. Dalam proses hegemoni dalam bahasa mitos pada Timba Lingkok Ratu ada beberapa paparan dari para responden sebagai berikut:

"Menurut saya bahwa proses hegemoni terjadi melalui bahasa lisandimasyarakat dimana penuturnya mencoba untuk membantu orangyang dianggap mendapat musibah terutama orang-orang yangmengidap penyakit. Penutur disini bercerita kepada orang yang mengidap penyakit tersebut tentang pengalamannya sendiri ataupunpengalaman orang lain yang sudah berobat kesana dan berhasilsembuh. Jadi proses hegemoni itu terjadi dengan memberikanpandangan positif kepada orang lain dan menyuguhkan bukti-buktiyang sudah dialami sekalipun bukti tersebut belum tentukebenarannya (Wawancara dengan Abdul Latif tanggal 25 Januari2017 jam 16.45 Wita)".

"Proses hegemoni itu sebenarnya seperti sales sepeda motor yangmencari kostumer, dengan berbagai bujukan dan hal-hal yang menarikyang disuguhkan akhirnya kostumer tersebut tertarik dan maumembeli sepeda motor. Begitu juga dengan proses hegemoni dalambahasa mitos, jadi mereka menceritakan hal-hal yang menurut sayatidak masuk akal akan tetapi karena orang tersebut kurangberpendidikan akhirnya percaya dan mencoba untuk mengikuti apayang telah diceritakan kadang juga orang tersebut berpendidikan tapimereka merasa tidak ada salahnya untuk mencoba (Wawancaradengan Gatot Suherman tanggal 25 Januari 2017 jam 17.00 Wita)".

"Proses hegemoni terjadi dari mulut kemulut atau dari lisan kelisansehingga banyak orang yang meyakininya (Wawancara dengan InaqRukaiyah tanggal 22 Januari 2017 jam 16.30 Wita)".

Dari ketiga pendapat diatas, dapat disimpulkan bahwa proses hegemoni dalam bahasa mitos Timba Lingkok Ratu di Desa Masbagik Utara berawal dari sebuah keyakinan yang bersifat tahayyul, kemudian keyakinan ini disebar luaskan dari mulut kemulut yaitu orang yang 
menghegemoni dan orang yang dihegemoni. Orang yang menghegemoni menyampaikan bahwa Timba Lingkok Ratu itu dapat dijadikan sebagai obat dengan cara mandi dan mengambil airnya, kemudian menyuguhkan bukti-bukti seperti cerita orang yang sudah berobat disana ataupun pengalaman-pengalamannya sendiri yang sudah mengambil syarat disana dengan tujuan untuk memperkuat keyakinan orang yang sedang dihegemoni.

Selanjutnya proses orang yang dihegemoni, berawal dari rasa penasaran yang selanjutnya diikuti oleh ingin membuktikan kebenaran dari cerita tersebut. Dengan didorong oleh rasa keinginan yang kuat, akhirnya mereka yang terhegemoni mencoba berobat di Timba Lingkok Ratu tersebut dan melakukan semua hal yang sudah menjadi syarat berobat disana. Dari proses tersebut akan menimbulkan dua kemungkinan, yang pertama ketika orang yang terhegemoni dapat sembuh maka akan menyebabkan proses hegemoni baru yaitu orang ini akan siap menghegemoni orang lain lagi. Kedua ketika orang yang terhegemoni merasa gagal untuk sembuh, maka kemungkinan besar proses hegemoni ini akan berhenti disini.

Adapun bentuk bahasa yang digunakan untuk memperkuat keyakinan Masyarakat terhadap Timba Lingkok Ratu ketika proses hegemoni terjadi adalah bahasa yang bersifat persuasif atau mempengaruhi bahkan bahasa paksaan, sebagai contoh "beberapa orang yang sudah berobat disana dapat sembuh dari penyakitnya”. Hal ini kemudian disampaikan dari lisan kelisan sehingga sampai kepada orang yang sakit. Akhirnya, dengan didorong oleh keinginan untuk sembuh dan gaya penyampaian yang begitu meyakinkan orang tersebut terhegemoni sehingga orang yang sakit mengikuti apa yang dikatakan oleh penutur. Karena adanya suatu kekuatan yang ditanamkan kepada orang yang terhegemoni itu sehingga akhirnya mereka melakukan hal tersebut.

Dari uraian diatas dapat ditemukan bahwa dalam proses hegemoni terdapat unsur yang disebut power dan practice. Power artinya kekuatan yaitu sejauh mana kekuatan orang yang menghegemoni itu terhadap objek yang dihegemoni. Semakin kuat kuat power sesorang yang menghegemoni maka cenderung akan semakin berhasil. Practice artinya menjalankan yaitu sejauh mana objek (orang yang terhegemoni) menjalankan power atau kekuatan tersebut. Hal ini sesuai dengan teori yang dikemukakan oleh Sujarwa (2010:19) dalam bukunya tentang Mitos Dibalik Kisah-Kisah Sinetron dalam Perspektif Hegemoni dan Kapitalisasi, Dia menyatakan bahwa Instumen transformasi seperti media televisi dalam proses hegemoni berperan penting dari kelompok orang yang mempunyai power dan practice kepada kaum yang dianggap lemah melalui karya-karya sinetronya.

\section{Bukti-bukti yang Memperkuat Keyakinan Masyarakat ketika Proses Hegemoni}

Beberapa bukti-bukti yang memperkuat keyakinan seseorang ketika proses hegemoni itu berlangsung sebagai berikut:

"penutur atau yang kita sebut dengan orang yang menghegemonimemberikan bukti berdasarkan pengalamannya sendiri maupunpengalaman orang lain contohnya seperti pengalaman Inaq Mar yangsudah berobat disana karena mengidap suatu penyakit setelah mandidan mengambil airnya dia tersebut berselang beberapa hari dapatsembuh

"Sejauh ini yang saya lihat tidak ada pengaruhnya antara kesembuhansuatu penyakit dengan mandi dan mengambil airnya, akan tetapikarena keyakinan yang begitu kuat yang tertanam pada orang yangmengambil syarat itu yang menyebabkan mereka sembuh karena dari segi kejiwaan akan mempengaruhi. Dan hal itulah yang dijadikansebagai bukti akan adanya pengaruh gaib"."Banyak buktinya orang yang pusing, sakit kepala, muntah-muntahbisa sembuh 
Berdasarkan penjelasan beberapa responden diatas, dapat disimpulkan bahwa proses hegemoni itu terjadi lewat bahasa lisan yang tujuannya untuk menolong orang sakit dengan cara menceritakan pengalaman sendiri maupun pengalaman orang lain dengan berbagai bukti yang dapat mempengaruhi pendengarnya sehingga mengikuti apa yang disarankan atau dianjurkan.

Bukti-buktinya adalah dapat menyembuhkan penyakit yang diderita, seperti yang sudah dialami oleh Inaq Mar yang sudah berobat disana. Selanjutnya banyak pula bukti-bukti yang lain seperti orang pusing, sakit kepala dan muntah-muntah dapat sembuh seperti yang dikatakan oleh salah satu responden yaitu Inaq Rukaiyah. Namun menurut peneliti, bukti-bukti tersebut belum dapat dijadikan sebagai bukti otentik karena menurut beberapa responden pula yaitu sekalipun mengambil syarat berobat di Timba Lingkok Ratu tersebut orang yang mengalami sakit tersebut tetap alternatif berobat ditempat lain seperti klinik, puskesmas maupun rumah sakit. Hal ini membuktikan bahwa Timba Lingkok Ratu tidak sepenuhnya dapat menyembuhkan penyakit karena selain tidak logis hal itu juga tidak ada hubungannya antara kesembuhan dan berobat dengan cara mandi dan meminum airnya. Oleh karena itu adanya keyakinan terhadap mitos Timba Lingkok Ratu itu semata-mata karena keyakinan yang sudah mentradisi pada masyarakat Desa Masbagik Utara.

\section{Bentuk-bentuk Bahasa yang Digunakan ketika Menyampaikan Mitos Timba Lingkok Ratu}

Bahasa adalah sebagai alat komunikasi yang digunakan dalam berinteraksi dengan sesama manusia di masyarakat. Bahasa sangat berperan penting dalam proses penyampaian Mitos Timba Lingkok Ratu yang berada di Desa Masbagik Utara. Dalam proses penyampaiannya sebagian besar masyarakat Masbagik Utara berasal dari suku Sasak, oleh karena itu bahasa yang digunakan juga termasuk dalam rumpun bahasa Sasak. Sebagai mana yang dijelaskan oleh beberapa responden sebagai berikut:

Bentuk bahasa yang digunakan ketika penyampainnya berisibahasa Sasak yang termasuk lakaqlakaq sebagai contoh

\section{"Tabeqtabeqdenda/RatuPutriAnjanil}

tiangnunasmedoleqpegedengnaplinggihleqAiqTimbaLingkokRatuNikisebagaisarathilangan gpenyakittiang.

berkatLaailahaillalloh"(WawancaradenganGatotSuhermantanggal25Januari jam17.20Wita)".

"Bentukbahasayangdigunakankadangberisilelakakatausejenispantunsebagai contoh

"telupempangbageqskeqpempangcemareteluanak bakeq sekeq ojok batare berkat laailahaillallah”

maknanya adalah supaya apa yang kita lakukan itu pada TimbaLingkok Ratu itu tidak mendapat halangan dari mahluk halus(Wawancara dengan Abdul Latif tanggal 23 Januari 2017 jam17.00 Wita)".

\section{Proses Hegemoni dalam Bahasa Mitos Timba Lingkok Ratu}

Praktik hegemoni adalah sebuah kegiatan yang pasti terjadi disetiap kehidupan manusia. Berkuasa dan dikuasai menjadi hal yang wajar terjadi disekitar kita. Hegemoni tidak akan lepas dari bahasa sebagai alat yang tepat dalam praktik hegemoni. Pada dasarnya hegemoni merupakan alat yang positif, namun akan menjadi sangat negatif apabila tidak terjadi kontrol terhadap hegemoni. Sebuah ketidakmungkinan untuk menghindari praktik hegemoni dengan media bahasa, yang bisa kita lakukan adalah memahami apa itu Hegemoni dan mengontrol Hegemoni tersebut agar tetap 
bernilai positif atau konstruktif, tentunya pada hegemoni dengan media bahasa yang lebih mengedepankan intelektualitas dan moral dalam, penguasaan terhadap manusia lain. Pengusaan ini sekali lagi bukan untuk hal yang negatif, melainkan hal-hal yang sifatnya membangun manusia yang kita hegemoni.

Berkaitan dengan hasil penelitian yang sudah dilakukan oleh peneliti bahwa proses hegemoni dalam bahasa mitos Timba Lingkok ratu di Desa Masbagik Utara berawal dari sebuah keyakinan yang bersifat tahayyul, kemudian keyakinan ini disebar luaskan dari mulut kemulut yaitu orang yang menghegemoni dan orang yang dihegemoni. Orang yang menghegemoni menyampaikan bahwa Timba Lingkok Ratu itu dapat dijadikan sebagai obat dengan cara mandi dan mengambil airnya.

Selanjutnya, orang yang menghegemoni menyuguhkan bukti-bukti agar memperkuat keyakinan orang yang sedang dihegemoni. Adapun bentuk bahasa yang digunakan untuk memperkuat keyakinan Masyarakat terhadap Timba Lingkok Ratu ketika proses hegemoni terjadi adalah bahasa yang bersifat persuasif atau mempengaruhi bahkan bahasa paksaan, sebagai contoh "beberapa orang yang sudah berobat disana dapat sembuh dari penyakitnya". Hal ini kemudian disampaikan dari lisan kelisan sehingga sampai kepada orang yang sakit.

Akhirnya, dengan didorong oleh keinginan untuk sembuh dan gaya penyampaian yang begitu meyakinkan orang tersebut terhegemoni sehingga orang yang sakit mengikuti apa yang dikatakan oleh penutur. Karena sangat kuatnya keyakinan orang yang terhegemoni itu sehingga akhirnya mereka dapat sembuh dari penyakitnya dan begitulah seterusnya.

Dengan kata lain, proses hegemoni dalam bahasa mitos Lingkok Ratu di Desa Masbagik Utara itu terjadi ketika pihak yang dominan (orang yang menghegemoni) menggambarkan dengan bahasa yang bersifat mempengaruhi terhadap pihak yang dihegemoni bahwa Timba LingkokRatu dapat mengobati segala macam penyakit jika seseorang mandi dan mengambil airnya. Hal ini terjadi karena Timba Lingkok Ratu tersebut dianggap mempunyai kekuatan gaib yang menyembuhkan orang yang sakit tanpa sadar mereka percaya tentang kekuatan-kekuatan mistis yang ada pada Lingkok Ratu tersebut.

\section{Kesimpulan}

Dari uraian pembahasan hasil penelitian di atas, disimpulkan bahwa proses hegemoni dalam bahasa Mitos Timba LingkokRatu di Desa Masbagik Utara terjadi karena beberapa hal sebagai berikut:1. Berawal dari sebuah keyakinan yang bersifat tahayyul, kemudiankeyakinan ini disebar luaskan dari mulut kemulut yaitu oleh pihakdominan (orang yang menghegemoni) kepada orang yang dihegemoni. 2. Bahasa yang bersifat persuasif atau mempengaruhi bahkan bahasa paksaandari pihak dominan dengan gaya penyampaian yang begitu meyakinkan. 3. Bukti-bukti yang disuguhkan oleh pihak dominan dengan tujuan untukmemperkuat keyakinan orang yang dihegemoni.Oleh karena itu dapat disimpulkan bahwa proses hegemoni dalambahasa Mitos Timba Lingkok Ratu di Desa Masbagik Utara adalah sebuahproses meyakinkan sesorang yang dilakukan oleh pihak dominan kepadamasyarakat terhadap Mitos Timba Lingkuk Ratu di Desa Masbagik Utaradengan pembuktian-pembuktian yang kuat. 


\section{Daftar Pustaka}

Achmad, 2014. Pamali \& Mitos Jawa Ilmu Kuno Antara Bejo dan Kesenian.Yogyakarta: Araska. Aini. 2015. Makna Sosial yang Terdapat dalam Mitos Potong Rambut Saat IstriHamil Desa Masbagik Timur. Oleh Jurusan Pendidikan IlmuPengetahuan Sosial STKIP Hamzanwadi Selong.

Arikunto. 2010. Prosedur Penelitian suatu Pendekatan Praktik. Jakarta: PT. Rineka Cipta.

El-Fanani. 2012. 101 Mitos dalam Psikologi. Yogyakarta: Araska.

Emzir, 2012. Metodelogi Penelitian Pendidikan: Kuantitatif dan Kualitatif.Jakarta: PT Rajagrafindo Persada.

Kurnia, Anton. 2016. Mencari Setangkai Daun Surga. Yogyakarta : PT. IRCiSoD.

Levi-Strauss, 2015. Pengertian Mitos. Diakses pada 08 Agustus 2016 darihttp://fariedmiftah.blogspot.co.id/2015/02/strukturalisme-levi-straussmitos-dan.html.

Moleong,2013. Metodologi Penelitian Kulitatif. Bandung Pt. Remaja RosdaKarya.

Parman, 1988. Kumpulan Mitos Sasak. Mataram : LPP Adat Sasak.

Puspitarini. 2014. Hegemoni Mitos Nyai Roro Kidul terhadap Kekuasaan Jawadalam Novel Sang

Nyai Karya Budi Sardjono. Oleh Jurusan SastraFakultas Ilmu Budaya Universitas Diponegoro.

Setiawan, 2015. Bentuk Makna dan Sesaji Mahase Lawung dalam Tradisi Ritualdi Keraton Surakarta Hadiningrat. Oleh Fakultas Bahasa dan SeniUniversitas Negeri Malang.

Sujarwa, 2010. Mitos dibalik Kisah-Kisah Sinetron dalam Perspektif Hegemonidan Kapitalisasi.

Yogyakarta: Pustaka Pelajar.

Suprapto. 2015. Ada Mitos dalam D.K.V. Jakarta : PT Lintas Kreasi Imaji. 